\title{
A Review of Niobium-Tantalum Separation in Hydrometallurgy
}

\author{
Olushola S. Ayanda ${ }^{1 *}$ and Folahan A. Adekola ${ }^{2}$ \\ ${ }^{1}$ Department of Chemistry, Faculty of Applied Sciences, Cape Peninsula University of \\ Technology, P.O. Box 652, Cape Town, South Africa. \\ ${ }^{2}$ Department of Chemistry, University of Ilorin, P.M.B 1515, Ilorin, Nigeria. \\ * Corresponding author: holysholay04@gmail.com
}

\begin{abstract}
Niobium and tantalum are chemically similar and are associated with each other in nature which makes it very difficult to separate. For many years, the separation of tantalum from niobium involved the fractional crystallization of potassium heptafluorotantalate away from potassium oxypentafluoroniobate monohydrate, this method has been supplanted by solvent extraction from fluoride-containing solutions by the use of solvent extractants such as Octanol, bis(2-ethylhexyl)phosphoric acid (DEHPA), Alamine 336, methyl isobutyl ketone (MIBK), tri-nbutyl phosphate (TBP) or cyclohexanone. A detailed review of the various processes involved in the breakdown treatment of niobium and tantalum primary sources, extraction and separation and newer processes of extraction as well as the various technique involved were discussed.
\end{abstract}

Keyword: Niobium, Tantalum, Columbite, Tantalite, Solvent extractant and Solvent extraction.

\section{INTRODUCTION}

Niobium is a rare, soft, grey and ductile transition metal with the symbol $\mathrm{Nb}$. It was discovered by Charles Hatchett, an English chemist (1765-1847), in 1801 [1]. Niobium is used in superconducting magnets, commemorative coins, medical device, jewelries, arc-tube seals, capacitors, optical lens, barometer, nuclear applications, superconducting RF cavities, electromagnetic radiation detector and it is used in nickel-, cobalt-, and iron-based super-alloys which are used in jet engines components, rocket sub-assemblies, heat resistant and combustion equipments [2, 3]. Tantalum was discovered by Anders Gustaf Ekeberg (1767-1813), in 1802 [1, 4]. It is a rare, hard, blue-gray, and lustrous transition metal, with the symbol Ta. Tantalum is 
used in alloys and wires, surgical instruments, reaction vessels and pipes, ultra high frequency electron tubes, lens, vacuum furnace parts, watches and tantalum being chemically inert is also used in capacitors as platinum substitute. Columbite, tantalite, columbite-tantalite (Coltan), pyrochlore, and euxenite constitute the major primary sources for niobium and tantalum and are located in Canada, Brazil, Nigeria, Zaire and Russia [5, 6].

These interesting elements are chemically similar and are associated with each other in nature. Separaton of niobium from tantalum was very difficult due to the chemical similarities of their oxides and due to their nearly identical atomic radii. For many years, the commercial technology for separating tantalum from niobium involved the fractional crystallization of potassium heptafluorotantalate away from potassium oxypentafluoroniobate monohydrate, a process discovered by Jean Charles Galissard de Marignac in 1866. The method has been supplanted by solvent extraction from fluoride-containing solutions [7].

\section{BREAKDOWN TREATMENT FOR PRIMARY SOURCES}

A large number of chemical treatment procedures for the breakdown of primary sources have been developed. Some of these have been adopted for commercial production while others have been tested on a fairly large scale. There are yet a few others that have been tested only on a laboratory scale. All these processes can essentially be divided into reduction to metallic or compound form, chlorination, alkaline fusion and acid dissolution (leaching) [7].

\subsection{Reduction}

One of the simplest methods for the breakdown treatment of primary concentrates of niobium and tantalum, particularly pyrochlore and columbite-tantalite, is direct reduction with aluminum or carbon [8], with or without the addition of iron or iron oxides termed aluminothermic and carbothermic reduction reaction.

\subsubsection{Aluminothermic and carbothermic reduction reactions}

Aluminothermic reduction reaction is highly exothermic and is thermodynamically feasible even at room temperature. During aluminothermic reduction, all the oxides that have free energy of formation less negative than that of alumina are reduced to metallic state and join the ferroalloy, whereas others report to the slag phase.

The carbothermic reduction reaction on the other hand, is thermodynamically feasible at high temperatures (generally over $1500^{\circ} \mathrm{C}$ ) and is highly endothermic in nature. Moreover, niobium and tantalum react with excess carbon and form carbides. 
Thus, the product in the case of aluminothermic reduction reaction is usually a ferroalloy, whereas that ensuring from carbothermic reduction may be a ferroalloy or alloy carbide mass containing practically all of the niobium and tantalum, together with many of the other elements that are present in the starting concentrate

\subsection{Chlorination}

Chlorination is a process for breakdown of ores and concentrates of many of the refractory metals [7], and even some of the commonly used metals are very attractive, an important features of chlorination, include the high reactivity of chlorine, relative ease in gasifying many of the constituents of the concentrates due to high volatility of most of the chlorides, and high water solubility of most of the chlorides. The chlorides formed can also be readily separated due to differences in their vapour pressures, or due to differences in reactivity with oxygen and/or water vapour and in their reducibility with hydrogen.

Thus, chlorination process is suitable not only for breakdown of the ore or concentrate but also for the separation/purification of various elements co-occurring in the concentrate and for reduction to metallic form.

\subsection{Alkaline Fusion}

Alkaline fusion is also one of the processes used for the breakdown of mineral ores concentrate. A large number of alkaline fluxes, such as caustic soda, soda ash, caustic potash, potassium carbonate, and a mixture of these, with or without addition of oxidizing agent such as sodium nitrate and sodium peroxide have been used by a large number of investigators [7].

Alkaline fusion in combination with acid leaching is one of the first methods to be adopted on an industrial scale to achieve simultaneous breakdown of columbite and tantalite concentrate and upgrading of niobium and tantalum values by leaching out of iron, manganese, tin, titanium and silicon.

\subsection{Leaching}

Leaching is the removal of material by dissolving them away from the solids. In chemical processes, industries use leaching but the process is usually called extraction, and organic solvents are often used. In industrial leaching, solvent and solids are mixed, allowed to approach equilibrium, and the two phases are separated. Liquids and solids move counter currently to the adjacent stages. The solvent phase, called the extract, becomes more concentrated as it contacts in the stagewise fashion the increasingly solute-rich solids. The raffinate becomes less concentrated in soluble material as it moves towards the fresh solvent phase [9]. 


\section{EXTRACTION AND SEPARATION OF NIOBIUM AND TANTALUM 3.1 Processes of Extraction and Separation}

After the breakdown treatment, the mixed oxides of tantalum $\mathrm{Ta}_{2} \mathrm{O}_{5}$ and niobium $\mathrm{Nb}_{2} \mathrm{O}_{5}$ are obtained. The first step in the processing is the reaction of the oxides with hydrofluoric acid [10]:

$\mathrm{Ta}_{2} \mathrm{O}_{5}+14 \mathrm{HF} \rightarrow 2 \mathrm{H}_{2}\left[\mathrm{TaF}_{7}\right]+5 \mathrm{H}_{2} \mathrm{O}$

$\mathrm{Nb}_{2} \mathrm{O}_{5}+10 \mathrm{HF} \rightarrow 2 \mathrm{H}_{2}\left[\mathrm{NbOF}_{5}\right]+3 \mathrm{H}_{2} \mathrm{O}$

The first industrial scale separation, developed by de Marignac, used the difference in solubility between the complex niobium and tantalum fluorides, dipotassium oxypentafluoroniobate monohydrate $\left(\mathrm{K}_{2}\left[\mathrm{NbOF}_{5}\right] \cdot \mathrm{H}_{2} \mathrm{O}\right)$ and dipotassium heptafluorotantalate $\left(\mathrm{K}_{2}\left[\mathrm{TaF}_{7}\right]\right)$ in water. Newer processes use the liquid extraction of the fluorides from aqueous solution by organic solvents like Octanol [11], bis(2-ethylhexyl)phosphoric acid (DEHPA) [12], Alamine 336 [13], methyl isobutyl ketone (MIBK) [14, 15, 16], tri-n-butyl phosphate (TBP) [17, 18] or cyclohexanone [19]. The complex niobium and tantalum fluorides are extracted separately from the organic solvent with water and either precipitated by the addition of potassium fluoride to produce a potassium fluoride complex, or precipitated with ammonia as the pentoxide [20]:

$\mathrm{H}_{2}\left[\mathrm{NbOF}_{5}\right]+2 \mathrm{KF} \rightarrow \mathrm{K}_{2}\left[\mathrm{NbOF}_{5}\right] \downarrow+2 \mathrm{HF}$

Followed by:

$2 \mathrm{H}_{2}\left[\mathrm{NbOF}_{5}\right]+10 \mathrm{NH}_{4} \mathrm{OH} \rightarrow \mathrm{Nb}_{2} \mathrm{O}_{5} \downarrow+10 \mathrm{NH}_{4} \mathrm{~F}+7 \mathrm{H}_{2} \mathrm{O}$

Several methods are used for the reduction to metallic niobium. The electrolysis of a molten mixture of $\mathrm{K}_{2}\left[\mathrm{NbOF}_{5}\right]$ and sodium chloride is one; the other is the reduction of the fluoride with sodium. With this method niobium with a relatively high purity can be obtained. In large scale production the reduction of $\mathrm{Nb}_{2} \mathrm{O}_{5}$ with hydrogen or carbon is used. In the process involving the aluminothermic reaction a mixture of iron oxide and niobium oxide is reacted with aluminium:

$3 \mathrm{Nb}_{2} \mathrm{O}_{5}+\mathrm{Fe}_{2} \mathrm{O}_{3}+12 \mathrm{Al} \rightarrow 6 \mathrm{Nb}+2 \mathrm{Fe}+6 \mathrm{Al}_{2} \mathrm{O}_{3}$

To enhance the reaction, small amounts of oxidizers like sodium nitrate are added. The result is aluminium oxide and ferroniobium, an alloy of iron and niobium used in the steel production $[21,22]$. The ferroniobium contains between 60 and $70 \%$ of niobium [23]. Without addition of iron oxide, aluminothermic process is used for the production of niobium. Further purification is necessary to reach the grade for superconductive alloys. Electron beam melting under vacuum is the method used by the two major distributors of niobium [11,24]. 


\subsection{Newer Processes of Extraction and Separation of Niobium and Tantalum}

A scheme of a proposed model by Amuda et al. [25] is presented in Figure 1. The figure incorporates mainly gravity, magnetic and electrostatic separation techniques with leaching as adjunct beneficiation technique to generate the various secondary ore concentrates.

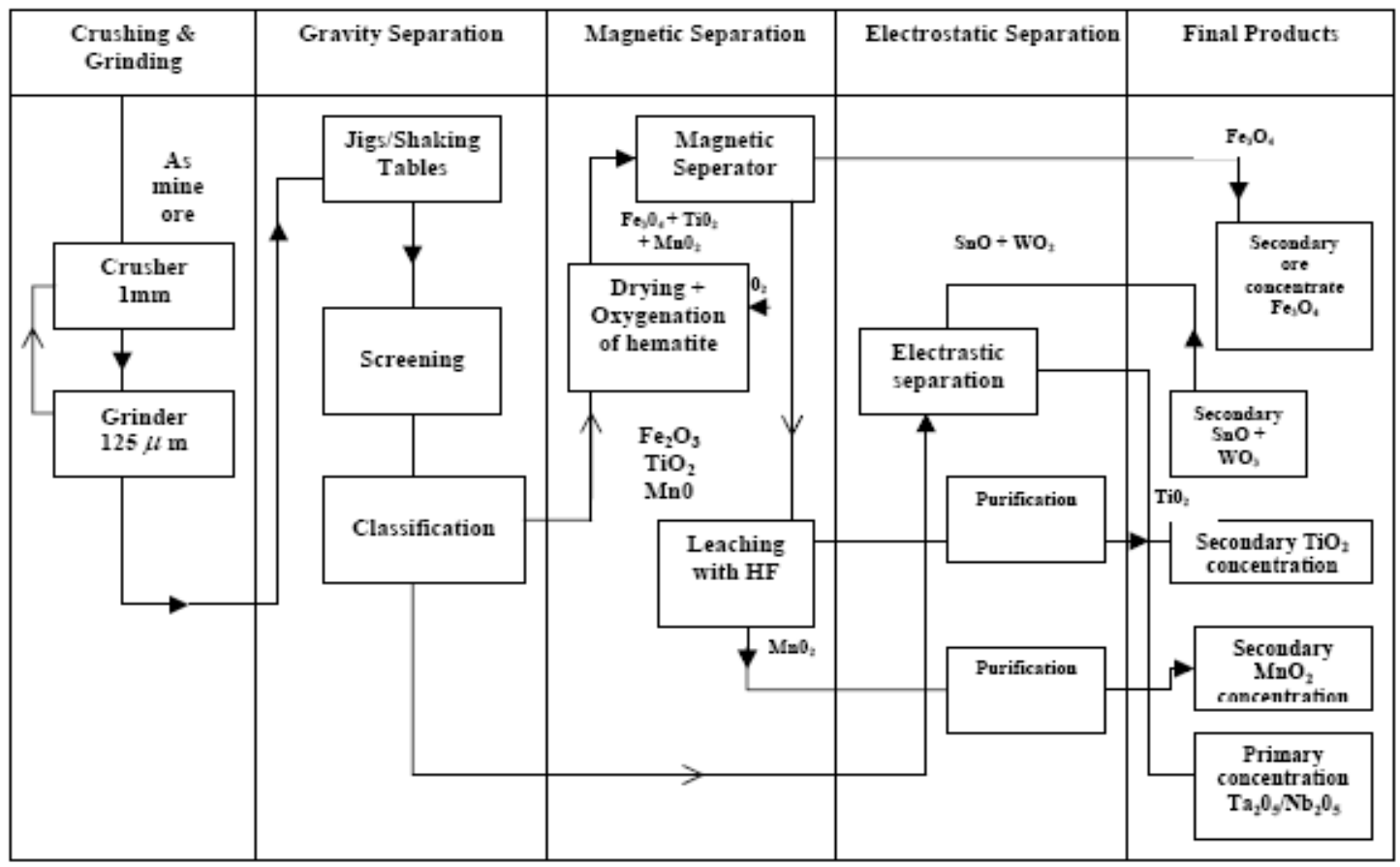

Fig. 1 Proposed Multi-Ore Constituent Concentration Model [25]

Agulyanski [11] reported the use of 2-octanol for the separation of niobium and tantalum. The process consists of the collective extraction of tantalum and niobium (5-7 extraction stages), scrubbing (6-9 stages), niobium stripping (5-7 stages) and Tantalum stripping (4-6 stages). He stated that sulphuric acid was added to $\mathrm{Ta}_{2} \mathrm{O}_{5}(50-60 \mathrm{~g} / \mathrm{l})$ and $\mathrm{Nb}_{2} \mathrm{O}_{5}(30 \mathrm{~g} / \mathrm{l})$ solutions in order to obtain an optimal acidity level.

Figure 2 below shows the extraction of tantalum and niobium versus $\mathrm{H}_{2} \mathrm{SO}_{4}$ concentration.

It is evident from the graph that the optimal $\mathrm{H}_{2} \mathrm{SO}_{4}$ concentration for tantalum extraction is about 2.5-3.5M while niobium begins to move into the organic phase at an $\mathrm{H}_{2} \mathrm{SO}_{4}$ concentration of 4$5 \mathrm{M}$.

Vin and Khopkar [12] developed a method for the reversed-phase extractive chromatographic separation of niobium and tantalum with bis(2-ethylhexyl)phosphoric acid (DEHPA). Niobium was extracted from 1-10M hydrochloric acid and stripped with $3 \mathrm{M}$ sulphuric acid containing $2 \%$ 
hydrogen peroxide while tantalum was extracted from $0.1-2 \mathrm{M}$ hydrochloric acid and was stripped with $0.1 \mathrm{M}$ hydrochloric acid containing $2 \mathrm{M}$ tartaric acid.

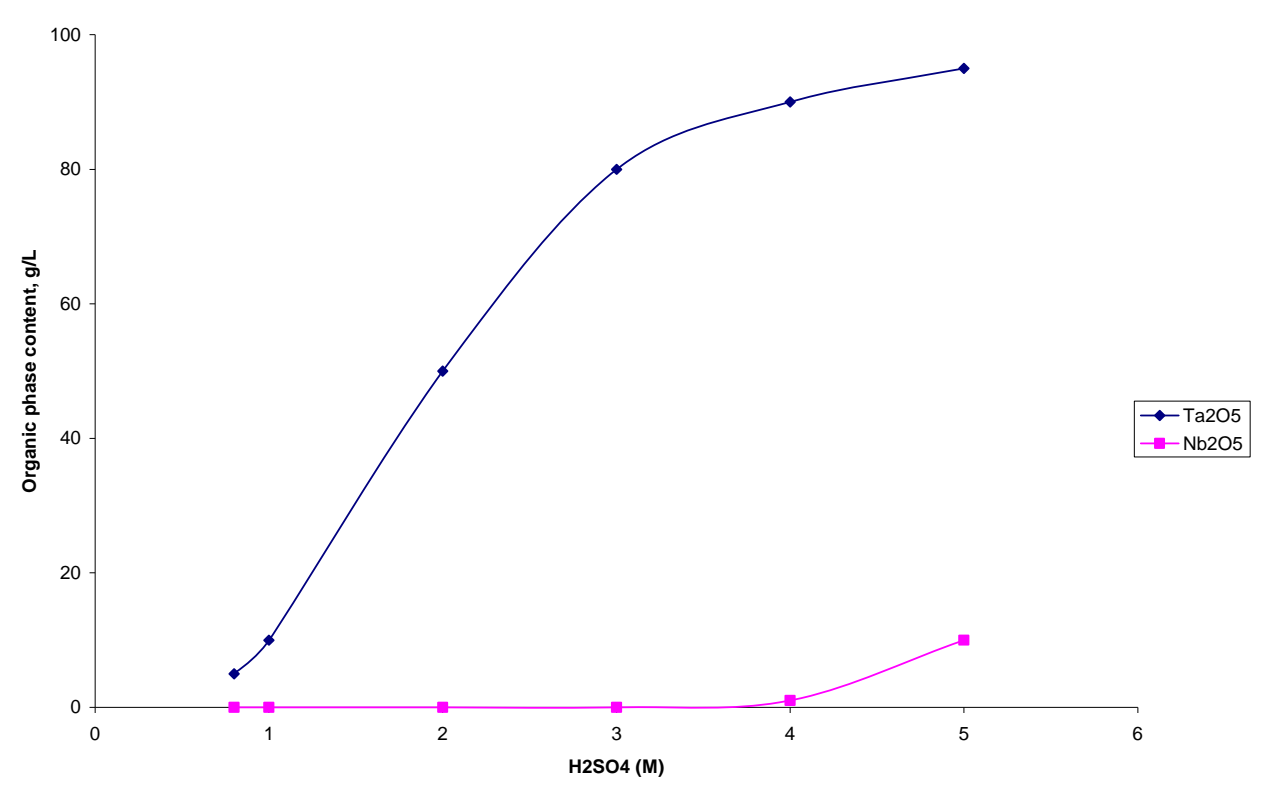

Fig. 2 Extraction of tantalum and niobium versus $\mathrm{H}_{2} \mathrm{SO}_{4}$ concentration

El hussaini and Rice [13] extracted niobium and tantalum from a leach liquor with tertiary amine, Alamine 336, using kerosene and xylene as diluents and n-decanol as a modifier. He investigated the effect of contact time, sulphate and fluoride concentrations in the aqueous phase, extractant concentration and aqueous to organic phase ratio. Both elements were extracted to different extents, with tantalum extraction slightly greater. The separation factor was greater for kerosene diluent. Selective stripping was performed using either $50 \mathrm{~g} / \mathrm{L}$ potassium hydroxide or $25 \mathrm{~g} / \mathrm{L}$ ammonium carbonate solutions for niobium and tantalum. Tantalum was stripped first and $\mathrm{Ta}(\mathrm{OH})_{5}$ was precipitated during the stripping process. The separation of niobium from tantalum was achieved at this point and niobium was then precipitated by adding ammonia.

Damodaran et al [17] carried out solvent extraction studies of niobium and tantalum in Indian with tributyl phosphate [TBP]. In his system niobium and tantalum were extracted together from the flouride solution at high acidities, and subsequently selectively stripped from the organic phase. He reported that a solvent concentration of 50\% TBP in kerosene gave optimum extraction characteristics. A 2-stage scrubbing of the tantalum-laden organic phase with $0.5 \mathrm{~N}$ HF-2.0 $\mathrm{N} \mathrm{H}_{2} \mathrm{SO}_{4}$ was said to reduce the niobium contamination in tantalum to less than $250 \mathrm{ppm}$. 
The pure tantalum in the form of $\mathrm{H}_{2} \mathrm{TaF}_{7}$ was then finally stripped with de-mineralized water. On completion of the extraction of tantalum, the aqueous raffinate was made up to $5.0 \mathrm{~N} \mathrm{HF-9.0N}$ $\mathrm{H}_{2} \mathrm{SO}_{4}$ and equilibrated with fresh TBP to extract the niobium. Niobium was then stripped with de-mineralized water.

Konghak [18] also carried out solvent extraction studies of niobium and tantalum in Korea using a mixer-settler with tributyl phosphate (TBP) as a solvent from the $\mathrm{HF}^{-} \mathrm{H}_{2} \mathrm{SO}_{4}-\mathrm{H}_{2} \mathrm{O}$ system. $\mathrm{He}$ performed scrubbing experiments to remove the impurities from the organic solution; the scrubbing was found effective under the conditions that the concentration of $\mathrm{H}_{2} \mathrm{SO}_{4}$ is $9 \mathrm{~N}$ and the ratio of the volumetric flow rate of the organic feed to the aqueous feed in the mixer-settler is 5 . In the stripping of niobium from the organic solution, he stated that the phase separation was much easier with $1 \mathrm{~N} \mathrm{H}_{2} \mathrm{SO}_{4}$ solution as a stripping medium than with water and proposed the flow diagram for the extraction and purification of niobium and tantalum to be represented by Figure 3 below:

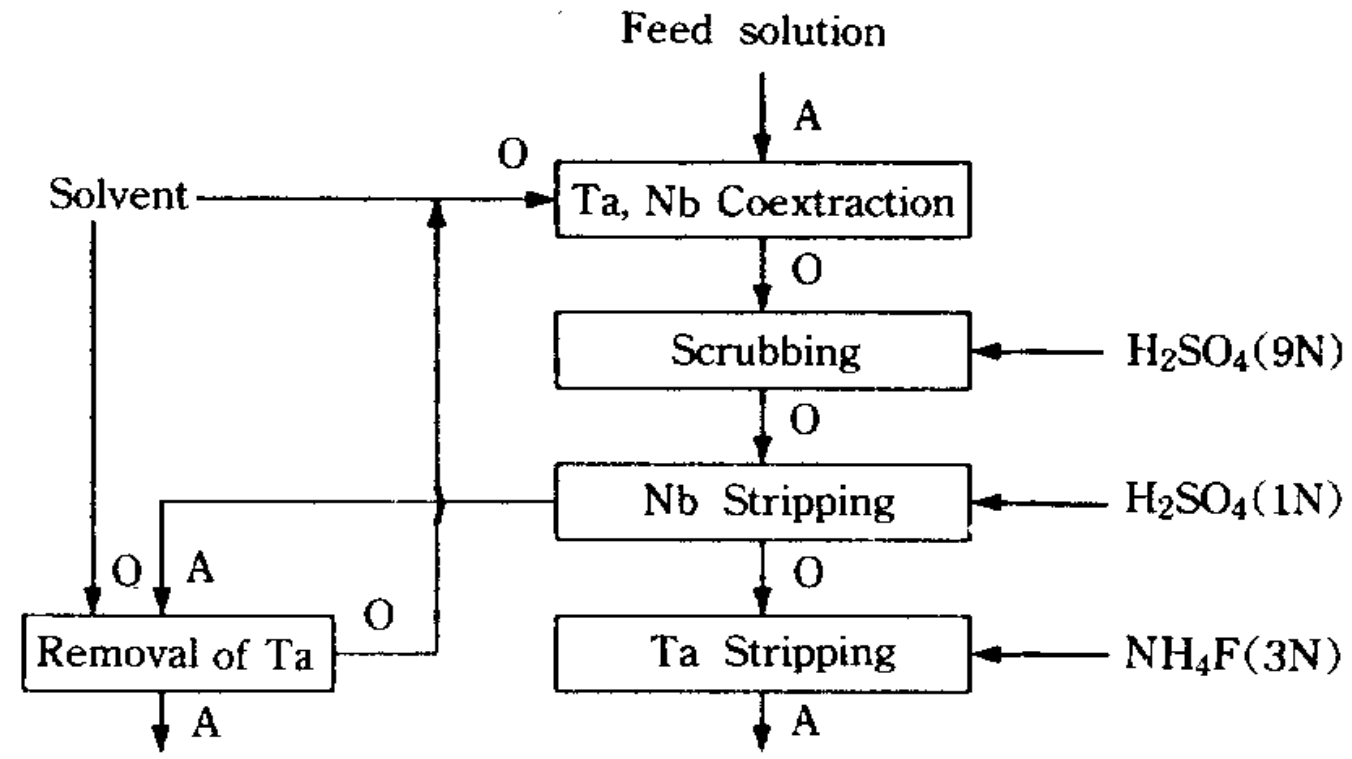

$\mathrm{Nb}$ rich Solution

Ta rich Solution

Fig. 3 Flow diagram for the extraction and separation of niobium and tantalum (O: organic phase; A: aqueous phase) [18]

Htet and Kay [14] studied the extraction of niobium oxide from columbite-tantalite concentrate of Thayet Kon Area in Nay Phi Taw (Pyinmana) using methyl isobutyl ketone. He reported that columbite-tantalite concentrate was leached with a mixture of hydrofluoric acid and sulfuric acid. The variation of acid concentration and leaching time were studied. 
The various concentrations of hydrofluoric acid and sulfuric acid were tested to obtain a condition to extract maximum amount of niobium in the filtrate and minimum amount of niobium in the residue. He likewise studied the effect of sulfuric acid, in which the concentration of $\mathrm{H}_{2} \mathrm{SO}_{4}$ was varied from 1-5N. According to his leaching tests, the concentration of $6 \mathrm{~N} \mathrm{HF}$ and the concentration of $1 \mathrm{NH}_{2} \mathrm{SO}_{4}$ were chosen because these conditions gave minimum amount of niobium oxide in the residue.

In order that he recovered niobium oxide from the pregnant solution, solvent extraction method using MIBK was carried out. Two stages were employed.

By adding $\mathrm{NH}_{4} \mathrm{OH}$ to the pregnant solution, precipitation took place until $\mathrm{pH} 11$ was reached. The precipitate and sodium hydroxide were put in a porcelain crucible and was placed in the muffle furnace. $\mathrm{HCl}$ digestion was necessary to remove impurities. The fused mass from caustic fusion was put in a beaker and leached for $1 / 2 \mathrm{hr}$. Calcinations was further performed for the production of pure niobium oxide.

He established the flow diagram for the extraction of niobium oxide as shown in figure 4 below:

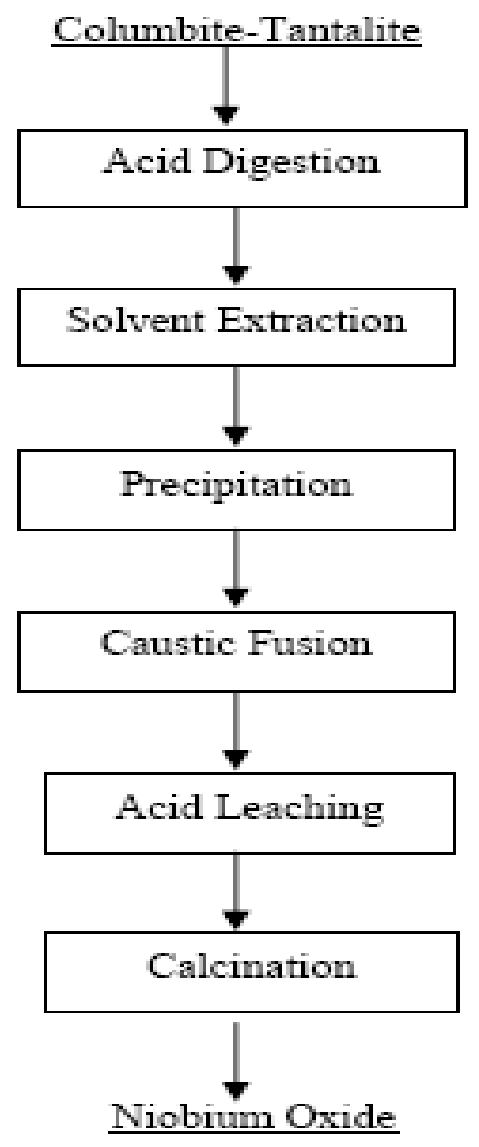

Fig. 4 Flow Diagram for the Extraction of Niobium Oxide 
Thakur [19] reported that a solution containing tantalum and niobium along with some impurities was subjected to solvent extraction (SX) treatment using the extractant MIBK or TBP. Both niobium and tantalum extract at high concentration of $\mathrm{H}_{2} \mathrm{SO}_{4}(>8 \mathrm{~N})$, but only tantalum extracts at lower acidity $(3 \mathrm{~N}-8 \mathrm{~N})$. Initially niobium and tantalum are extracted together in the organic phase (MIBK) at greater than $8 \mathrm{~N} \mathrm{H}_{2} \mathrm{SO}_{4}$. Under these conditions most of the impurities such as iron, manganese and magnesium remain in the aqueous phase. Organic phase (MIBK) containing niobium and tantalum was then brought into contact with fresh aqueous phase containing less than $8 \mathrm{~N}$ (preferably around $3 \mathrm{~N}$ ) $\mathrm{H}_{2} \mathrm{SO}_{4}$. Under this condition only niobium was back extracted in the aqueous phase keeping tantalum in the organic phase. The back extracted aqueous niobium was again re-extracted with MIBK to remove traces of tantalum (i.e., to reextract traces of tantalum from niobium).

Then ammonia was added to the aqueous solution containing pure niobium to precipitate niobium oxide hydrate. Oxide hydrate of niobium was then separated by filtration, dried and calcined in heated chambers or rotary furnaces. Niobium oxide thus obtained is of high purity. He reported that the extractants are amenable to degradation due to high concentrations of acids, in particular $\mathrm{HF}$.

Jainex Industrial Corporation [16] likewise reported that tantalum and niobium were extracted from their ores after concentration by chemical means rather than by smelting. The concentrates are attacked by $\mathrm{HF} / \mathrm{H}_{2} \mathrm{SO}_{4}$ which brings the tantalum and niobium compounds into solution. The acid solution was mixed thoroughly with MIBK (methyl-iso-butyl ketone) which dissolves the tantalum and niobium compounds into the ketone while leaving impurities in the aqueous solution. The organic and inorganic solutions form separate layers and the organic (ketone) solution could be separated from the aqueous layer (liquid-liquid separation). The niobium was then stripped with dilute acid, and the tantalum subsequently extracted by acid ammonium fluoride. For tantalum, the metal could be produced in powder form by sodium reduction of the fluoride.

Kigoshi [26] also developed a nitrofluor process for the extraction of niobium and tantalum from columbite. He reported that the nitrofluor process provides a method of dissolving columbite in a non-aqueous inorganic solvent, purifying the niobium and tantalum and separating them by a volatile separation technique. A niobium-tantalum separation was made possible by utilizing the difference of volatility of the complex fluorides formed with an $\mathrm{HF}-\mathrm{N}_{2} \mathrm{O}_{3}$ azeotrope used for the disintegration of the ore. A general flowsheet for treating typical columbite or tantalite by a nitrofluor process as proposed was represented in figure 5 below [26]: 


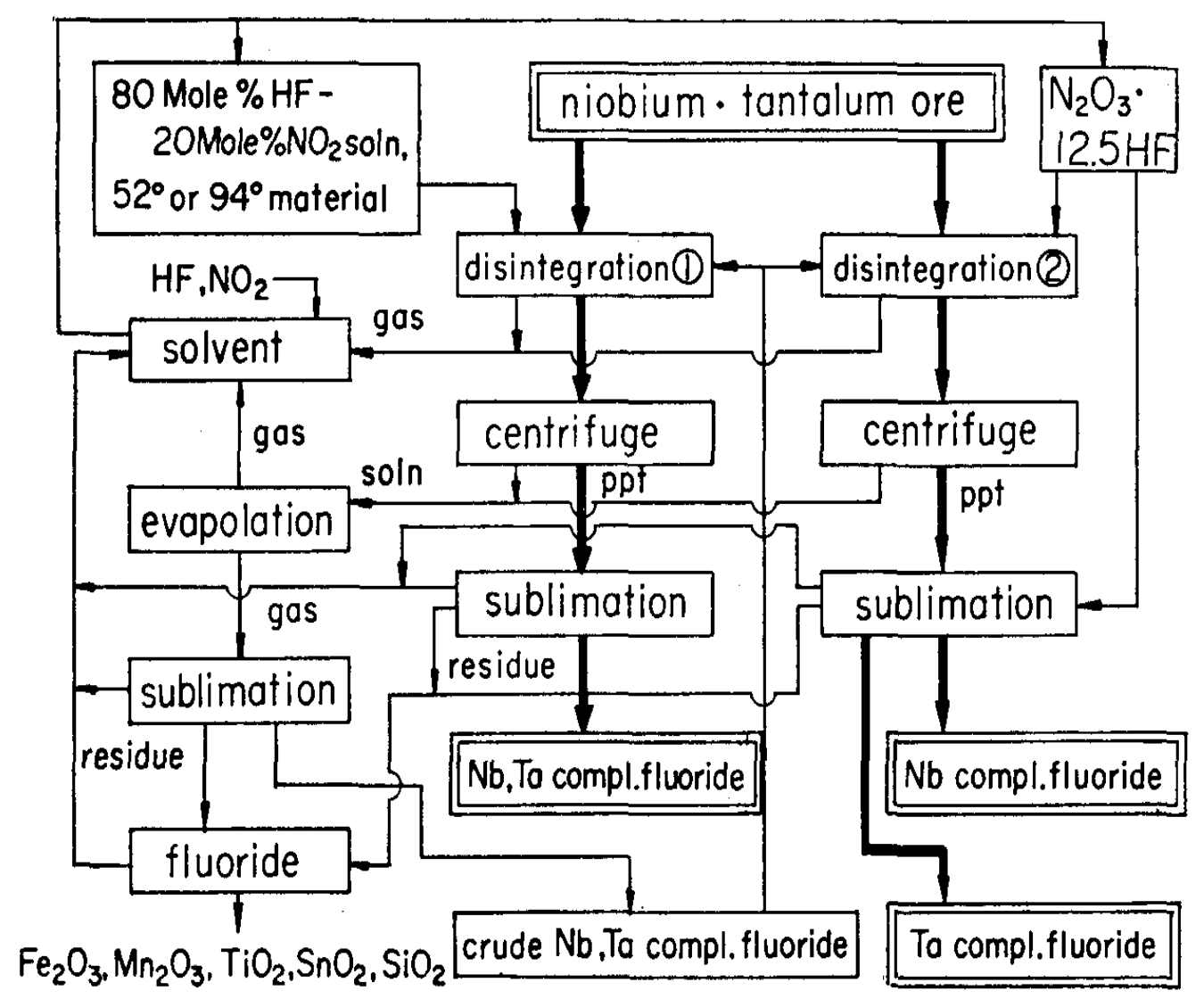

Fig. 5 Nitrofluor process for treating $\mathrm{Nb}$ and $\mathrm{Ta}$ ore

The World Intellectual Property Organization [27] described a process for the treatment of raw material containing tantalum and/or niobium in which the raw material was processed by a solution containing ammonium fluoride at the boiling point for not more than 10 hours, the obtained mixture was leached using water or a solution containing ammonia at a temperature below $100^{\circ} \mathrm{C}$ for not more than 1 hour. The obtained solution was filtrated giving a main filtrate containing $\mathrm{Ta}_{2} \mathrm{O}_{5}$ and/or $\mathrm{Nb}_{2} \mathrm{O}_{5}$ and the filtrate was processed by a solution of $\mathrm{NH}_{3}$ in not more than 30 minutes. A sediment was separated by filtering and was then dried and calcinated at a temperature not higher than $450^{\circ} \mathrm{C}$ for not more than 2 hours.

The sediment was then dissolved in a solution containing $\mathrm{F}$ and $\mathrm{HF}$ and the obtained solution undergoes a multistage liquid extraction, during which separation of components of tantalum and/or niobium was achieved in the form of their complex fluoro acids and fluorosalts in an aqueous solution. To the obtained fluoride containing solution of niobium and tantalum, respectively, an ammonium solution was added. From the solution, oxide hydrates of niobium and tantalum respectively were released and the released oxide hydrates were calcinated giving a product containing more than $99 \%$ niobium and tantalum, respectively. 


\section{CONCLUSION}

The extraction and separation of niobium and tantalum by solvent extraction has proven to be simple, rapid and very efficient. Solvent extraction is largely applied in the purification processes in chemical and metallurgical industries and it likewise provides selective extraction and recovery of niobium and tantalum from aqueous solution. This present review also shows that the extraction and separation of niobium and tantalum from their ores involves the breakdown treatment of the source, extraction and separation by varying experimental conditions, precipitation, filtration, washing, drying and calcinations. Other techniques such as gravity, magnetic and electrostatic separation techniques may be coupled as adjunct to obtain a purer niobium and tantalum.

\section{REFERENCES}

1. TIC, Tantalum and Niobium-Early History. http://tanb.org/history, retrieved on 30/10/2009.

2. Wikipedia, the free encyclopedia, Niobium. http://en.wikipedia.org/wiki/Niobium, retrieved on $05 / 10 / 2009$.

3. V. Erick (2007) Coltan - Columbo tantalite, http://www.eurosinolink.com/pdf/sdpm003v1 coltan.pdf, retrieved 28/09/2009.

4. Tantalum, http://rsc.org/Chemsoc/VisualElements/pages/pdf/tantalum.PDF, retrieved 28/09/2009

5. N. Thakur (2009) Niobium and Tantalum, http://knol.google.com/k/narayan-thakur/niobiumand-tantalum/2kwb871ek26nr/66, retrieved on 23/09/2009.

6. Wikipedia, the free encyclopedia, Coltan. http://en.wikipedia.org/wiki/Coltan, retrieved on 23/09/2009.

7. C. K. Gupta, A. K. Suri (1994) Extractive Metallurgy of Niobium, CRC Press, pp. 1-16, ISBN 0849360714.

8. Wikipedia, the free encyclopedia, Reduction http://en.wikipedia.org/wiki/Reduction, retrieved on $23 / 09 / 2009$.

9. http//:www.bungah@rpi.edu School of Engineering, Rensselaer Polytechnic Institute, Troy, NY 12180, 2001

10. D. J. Soisson, J. J. McLafferty, J. A. Pierret (1961) Staff-Industry Collaborative Report, Tantalum and Niobium Industrial and Engineering Chemistry, 53 (11), 861-868.

11. A. Agulyansky (2004) The Chemistry of Tantalum and Niobium Fluoride Compounds, Elsevier, pp. 1-11. ISBN 9780444516046.

12. Y. Y. Vin, S. M Khopkar (1991) Separation of niobium and tantalum by extraction chromatography with bis(2-ethylhexyl)phosphoric acid, Talanta, 38 (9), 971-5.

13. O. M. El hussaini, N. M. Rice (2004) Liquid-liquid extraction of niobium and tantalum from aqueous sulphate/fluoride solutions by a tertiary amine, Hydrometallurgy, 72, 259-267. ISSN 0304-386X. 
14. H. H. Htet, T. L. Kay (2008) Study on Extraction of Niobium Oxide from ColumbiteTantalite Concentrate, World Academy of Science, Engineering and Technology, 46, 133135.

15. Free patents online, Process for the recovery and separation of tantalum and niobium. United States Patent 5209910 http://www.freepatentsonline.com/5209910.html, retrieved on 30/10/2009.

16. Jainex Industrial Corporation, Tantalum (Ta), http://jainexmetals.com/tantalum.htm, retrieved on $30 / 10 / 2009$.

17. A. D. Damodaran, S. G. Deshpande, A. A. Majmudar and M. S. Sastri (1969) Extraction and Utilization of Pure Niobium and Tantalum from Indian Ores. Bhabha Atomic Research Center, Trombay, Bombay, 36, No. 5, pp. 306-318.

18. H. Konghak (1991) Solvent Extraction of Tantalum and Niobium Using Mixer-Settler, Korea Institute of Chemical Engineers, 29, 305-343.

19. N. Thakur (2009) Niobium and Tantalum, http://knol.google.com/k/narayan-thakur/niobiumand tantalum/2kwb871ek26nr/66, retrieved on 23/09/2009.

20. N. Izabela; Z. Maria (1999) Niobium Compounds: Preparation, Characterization, and Application in Heterogeneous Catalysis, Chemical Reviews, 99 (12), 3603-3624.

21. G. Tither (2001) Progress in Niobium Markets and Technology 1981-2001, Minerals, Metals and Materials Society, Metals and Materials Society Minerals. Ed. Niobium Science \& Technology: Proceedings of the International Symposium Niobium 2001 (Orlando, Florida, USA) (Niobium 2001 Ltd, 2002). ISBN 9780971206809.

22. C. Dufresne, G. Goyette (2001) The Production of Ferroniobium at the Niobec mine 19812001, Minerals, Metals and Materials Society, Metals and Materials Society Minerals. Ed. Niobium Science \& Technology: Proceedings of the International Symposium Niobium 2001 (Orlando, Florida, USA) (Niobium 2001 Ltd, 2002). ISBN 9780971206809.

23. J. Kouptsidis (2001) Niob für TESLA (in German), Deutsches Elektronen Synchrotron DESY.http://tesla.desy.de/new_pages/TESLA_Reports/2001/pdf_files/tesla2001-27.pdf, retrieved 2008-09-02.

24. A. Choudhury, E. Hengsberger (1992) Electron Beam Melting and Refining of Metals and Alloys, The Iron and Steel Institute of Japan International, 32 (5), 673-681.

25. M. O. H Amuda, D. E. Esezobor, G. I. Lawal (2007) Adaptable Technologies for LifeCycle Processing of Tantalum Bearing Minerals, Journal of Minerals \& Materials Characterization \& Engineering, 6, No.1, pp 69-77.

26. A. Kigochi (1972) The extraction of Niobium and Tantalum from Columbite by the Nitrofluor Process. The Research Institute of Mineral Dressing and Metallurgy, pp. 9.

27. World Intellectual Property Organization (2000) Treating Niobium and/or Tantalum Containing Raw Materials, (WO/2000/024943). http://www.wipo.int/pctdb/en/wo.jsp?WO=2000024943\&IA=SE1999001888\&DISPLAY=C LAIMS, retrieved on 12/10/2009. 